\title{
Effect of Deformation and Aging on Properties of Al-4.1\%Cu-1.4\%Mg Aluminum Alloy
}

\author{
Hao Wang, ${ }^{1}$ Changsheng Li, ${ }^{1}$ Jing Li, ${ }^{2}$ Xinglong Wei, ${ }^{3}$ and Ruibin Mei ${ }^{1}$ \\ ${ }^{1}$ State Key Laboratory of Rolling and Automation, Northeastern University, Shenyang, Liaoning 110819, China \\ ${ }^{2}$ School of Management, Harbin Institute of Technology, Harbin, Heilongjiang 150001, China \\ ${ }^{3}$ Benxi Steel Co. Ltd., Benxi, Liaoning 117021, China
}

Correspondence should be addressed to Hao Wang; neuwanghao@gmail.com

Received 10 July 2013; Accepted 4 August 2013

Academic Editors: Y. X. Gan, V. Ji, and A. O. Neto

Copyright (C) 2013 Hao Wang et al. This is an open access article distributed under the Creative Commons Attribution License, which permits unrestricted use, distribution, and reproduction in any medium, provided the original work is properly cited.

\begin{abstract}
Deformation scheme and preheat treatment of $\mathrm{Al}-4.1 \% \mathrm{Cu}-1.4 \% \mathrm{Mg}$ aluminum alloy are chosen, homogenizing annealing at $430^{\circ} \mathrm{C}$ for $1.5 \mathrm{~h}$, cooling to $250^{\circ} \mathrm{C}$ in furnace at a cooling rate of less than $30^{\circ} \mathrm{C} / \mathrm{h}$ and then cooling to room temperature to make $\mathrm{Al}-4.1 \% \mathrm{Cu}-1.4 \% \mathrm{Mg}$ aluminum alloy annealed fully. Heat treatment tests of $\mathrm{Al}-4.1 \% \mathrm{Cu}-1.4 \% \mathrm{Mg}$ aluminum alloy mainly consisting of rolling and aging were conducted, and the optimum peak of aging mechanism is $190^{\circ} \mathrm{C} / 12 \mathrm{~h}$. Through comparison of microstructure and mechanical properties with different deformation rates and aging mechanisms, effect of deformation rates and aging mechanism on properties of $\mathrm{Al}-4.1 \% \mathrm{Cu}-1.4 \% \mathrm{Mg}$ aluminum alloy was analyzed, and the optimum double peak of aging mechanism is $135^{\circ} \mathrm{C} / 7 \mathrm{~h}+185^{\circ} \mathrm{C} / 14 \mathrm{~h}$. Orthogonal experiments were carried out to analyze mechanical and electrical properties of tested materials before and after deformation, and the effect of aging mechanism on $\mathrm{Al}-4.1 \% \mathrm{Cu}-1.4 \% \mathrm{Mg} \mathrm{Al}$ alloy was analyzed, and the optimum regression of aging mechanism is $190^{\circ} \mathrm{C} / 12 \mathrm{~h}+240^{\circ} \mathrm{C} / 40 \mathrm{~min}+190^{\circ} \mathrm{C} / 12 \mathrm{~h}$. Aging scheme is closely related to corrosion resistance of $\mathrm{Al}-4.1 \% \mathrm{Cu}-1.4 \% \mathrm{Mg}$ aluminum alloy, and three different aging schemes can improve the corrosion resistance. The exfoliation corrosion evaluation results show that the aging effect on exfoliation corrosion ability order is RRA > two-step aging > peak aging.
\end{abstract}

\section{Introduction}

After a combination of solution treatment and aging, Al-CuMg aluminum alloy possesses high strength, which makes it a most widely used aluminum alloy [1]. As a duralumin, $\mathrm{Al}-\mathrm{Cu}-\mathrm{Mg}$ aluminum alloy has a good molding ability and mechanical processing properties. $\mathrm{Al}-\mathrm{Cu}-\mathrm{Mg}$ aluminum alloy products mainly consist of plates, wires, and bars, which are mainly developed for the aircraft skin, bulkheads, wing ribs, engine components, and automobile industries $[2,3]$.

In order to develop aluminum alloy with high strength, high toughness, and high resistance to stress corrosion cracking, many trials and studies were carried out for decades, and there are mainly two effective methods, thermomechanical treatment (TMT) and retrogression and reaging (RRA) $[4,5]$. TMT is a process combining both strain hardening after the plastic deformation and phase transformation strengthening after heat treatment [6]. The basic principle is to increase the density of defects in the metal deformation and change its distribution; deformation defects generated by phase transition during heat treatment will affect nucleation and distribution of the new phases; at the same time, the formation of new phases will pin or block movement of dislocations defects, making defects stable and microstructure refined improving its strength and toughness [7]. Dislocation caused by deformation is often combined with a dislocation network through slipping or climbing movement to reduce energy; therefore, the microstructure of the treated $\mathrm{Al}-\mathrm{Cu}$ $\mathrm{Mg}$ aluminum alloy is with high dislocation density and substructures, and thermomechanical treatment is essentially substructure strengthening [8].

In 1974 B.M.Cina first proposed that after artificial aging is suitable for regression treatment, and later repeating the original artificial aging, which would effectively improve mechanical properties and corrosion resistance of aluminum alloy, and the heat treatment process is called 
TABLE 1: Chemical composition of Al-4.1\%Cu-1.4\%Mg aluminum alloy (mass, \%).

\begin{tabular}{|c|c|c|c|c|c|c|c|c|c|}
\hline Elements & $\mathrm{Cu}$ & $\mathrm{Mg}$ & $\mathrm{Mn}$ & $\mathrm{Fe}$ & $\mathrm{Si}$ & $\mathrm{Zn}$ & $\mathrm{Ti}$ & $\mathrm{Ni}$ & $\mathrm{Al}$ \\
\hline Mass, $\%$ & 4.1 & 1.4 & 0.6 & 0.5 & 0.5 & 0.3 & 0.15 & 0.10 & $\mathrm{Bal}$ \\
\hline
\end{tabular}

TABLE 2: Selection of levels in stage aging orthogonal design.

\begin{tabular}{lcccc}
\hline Level & $\begin{array}{c}\text { First stage aging } \\
\text { temperature } /{ }^{\circ} \mathrm{C}\end{array}$ & $\begin{array}{c}\text { First stage aging } \\
\text { time/h }\end{array}$ & $\begin{array}{c}\text { Second stage aging } \\
\text { temperature } /{ }^{\circ} \mathrm{C}\end{array}$ & $\begin{array}{c}\text { Second stage } \\
\text { aging time } / \mathrm{h}\end{array}$ \\
\hline 1 & 105 & 4 & 180 & 14 \\
2 & 115 & 6 & 190 & 16 \\
3 & 125 & 8 & 200 & 18 \\
4 & 135 & 10 & 210 & 20 \\
\hline
\end{tabular}

RRA treatment [9]. Through peak aging, tensile strength of alloy could achieve ideal value, but the corrosion resistance decreases. In RRA, the temperature and time of second stage aging are critical to the whole aging process. However, to the best of the authors' knowledge, there have been few reports on deformation and aging treatment of $\mathrm{Al}-4.1 \% \mathrm{Cu}-$ $1.4 \% \mathrm{Mg}$ aluminum alloy. The purpose of the present study is to investigate the effect of the deformation and different aging treatments on the microstructure and mechanical properties of $\mathrm{Al}-4.1 \% \mathrm{Cu}-1.4 \% \mathrm{Mg}$ aluminum alloy, providing reference for its various industrial applications.

\section{Experimental Materials and Method}

2.1. Experimental Materials. The materials used in this research work were wrought heat treatable $\mathrm{Al}-4.1 \% \mathrm{Cu}-$ $1.4 \% \mathrm{Mg}$ aluminum alloy, whose chemical compositions are given in Table 1 .

2.2. Thermal Analysis. DSC thermal analysis is conducted in the EPM laboratory of Northeastern University with MDSCQ100 heat analyzer; samples are selected as a bulk sample of $5 \mathrm{~mm}$ side length cleaned with alcohol and acetone, respectively, before the test, with pure aluminum as a reference. The heating rate is $10^{\circ} \mathrm{C} / \mathrm{min}$, and the temperature range is selected between $300^{\circ} \mathrm{C}$ and $550^{\circ} \mathrm{C}$.

2.3. Homogenization Treatment. Annealing temperature was selected as $430^{\circ} \mathrm{C}$ for $1.5 \mathrm{~h}$, and the plate was cooled to less than $250^{\circ} \mathrm{C}$ with an air furnace cooling rate of $30^{\circ} \mathrm{C} / \mathrm{h}$ and then air cooled to room temperature.

2.4. Rolling. The slab after homogenization at $450^{\circ} \mathrm{C}$ is rolled from $30 \mathrm{~mm}$ at $470^{\circ} \mathrm{C}$ to $6.2 \mathrm{~mm}$ (total deformation ratio of $79 \%$ ), in which deformation ratios of $30 \%, 50 \%$, and $70 \%$ were achieved. After solid solution at $490^{\circ} \mathrm{C}$ for $1 \mathrm{~h}$, the slab was quenched in water immediately, and then it was cold-rolled to $1.4 \mathrm{~mm}$ sheet (deformation ratio of $77 \%$ ) at room temperature for the subsequent experiments.

2.5. Aging. After rolling and solution, the alloy was subjected to aging treatment immediately, and aging treatment is divided into peak aging, stage aging, and RRA in this experiment. For peak aging, the aging temperature was selected as $180^{\circ} \mathrm{C}, 190^{\circ} \mathrm{C}$, and $200^{\circ} \mathrm{C}$ with aging times of $2 \mathrm{~h}$, $6 \mathrm{~h}$, and $12 \mathrm{~h}$ to determine the optimum aging temperature. Then, the optimum temperature aging time was selected from $2 \mathrm{~h}, 4 \mathrm{~h}, 6 \mathrm{~h}, 8 \mathrm{~h}, 12 \mathrm{~h}, 16 \mathrm{~h}, 20 \mathrm{~h}$, and $24 \mathrm{~h}$ at the optimum aging temperature. In accordance with the characteristics of the stage aging, the first stage is a low-temperature preaging, generally $80^{\circ} \mathrm{C}$ lower than the peak aging temperature, and first stage aging time is usually about $6 \mathrm{~h}$ to ensure the stability of nucleation. The second stage aging is selected near the peak aging temperature, and the second stage aging time is generally about $16 \mathrm{~h}$ to ensure the effect of stabilizing. According to the above characteristics, the aging temperature and time range were selected as $105^{\circ} \mathrm{C} \sim 135^{\circ} \mathrm{C}$ for $4 \mathrm{~h} \sim 10 \mathrm{~h}$ in the first stage and $180^{\circ} \mathrm{C} \sim 210^{\circ} \mathrm{C}$ for $14 \mathrm{~h} \sim 20 \mathrm{~h}$ in the second stage, as shown in Table 2.

According to the experimental features of both peak aging parameters and RRA treatment, the first and third aging temperatures and times are the same as the peak aging temperature and time, and the second aging temperature was selected as $240^{\circ} \mathrm{C}$ and $280^{\circ} \mathrm{C}$, and the aging time is $20 \mathrm{~min}, 40 \mathrm{~min}$, and $60 \mathrm{~min}$, respectively. The specific RRA trial program is shown in Table 3.

2.6. Hardness, Conductivity Test. Hardness experiments were conducted using 430/450SVDTM Vickers hardness measurement instrument with a load of $49 \mathrm{~N}$ for a dwell time of 15 s. FD102 digital eddy current conductivity meter with an accuracy of $\pm 0.1 \%$ IACS was applied in conductivity measurement. The tensile specimens were got parallel to the rolling direction.

2.7. Corrosion Test. The qualitative analysis of the aluminum alloy was carried out according to ASTM G34-01. Plate sample size of interception is $15 \mathrm{~mm} \times 20 \mathrm{~mm} \times 2 \mathrm{~mm}$. According to different surfaces of the sample, the samples are first washed with acetone, ground and polished, and finally washed with distilled water and dried naturally at room temperature. Corrosive medium is EXCO solution $(4 \mathrm{~mol} / \mathrm{L}$ $\mathrm{NaCl}$ and $0.5 \mathrm{~mol} / \mathrm{L} \mathrm{KNO}_{3}+0.1 \mathrm{~mol} / \mathrm{L} \mathrm{HNO}_{3}$ ), the area ratio of the etched surface to corrosive media is $1500 \mathrm{~mL} / \mathrm{dm}^{2}$, and water bath temperature is maintained at $25 \pm 1^{\circ} \mathrm{C}$. The prepared sample was soaked in the etching solution to 
TABLE 3: Design of RRA tests.

\begin{tabular}{ccccccc}
\hline $\begin{array}{l}\text { No. } \\
\text { 1st stage aging } \\
\text { temperature } /{ }^{\circ} \mathrm{C}\end{array}$ & $\begin{array}{c}\text { 1st stage aging } \\
\text { time/h }\end{array}$ & $\begin{array}{c}\text { 2nd stage aging } \\
\text { temperature } /{ }^{\circ} \mathrm{C}\end{array}$ & $\begin{array}{c}\text { 2nd stage aging } \\
\text { time/min }\end{array}$ & $\begin{array}{c}\text { 3rd stage aging } \\
\text { temperature } /{ }^{\circ} \mathrm{C}\end{array}$ & $\begin{array}{c}\text { 3rd stage aging } \\
\text { time } / \mathrm{h}\end{array}$ \\
\hline 1 & 190 & 12 & 240 & 20 & 190 & 12 \\
2 & 190 & 12 & 240 & 40 & 60 & 190 \\
3 & 190 & 12 & 240 & 20 & 190 & 12 \\
4 & 190 & 12 & 280 & 40 & 190 & 12 \\
5 & 190 & 12 & 280 & 60 & 190 & 12 \\
6 & 190 & 12 & 280 & 190 & 12 \\
\hline
\end{tabular}

observe the surface variation of the specimen after different corrosion times. The specimens for observation are cleaned with $30 \% \mathrm{HNO}_{3}$ solution to remove surface corrosion products, and then etched sample surface was washed away the corrosion products and photographed in comparison with ASTM G34-01 standard, accomplish corrosion sample rating.

Corrosion levels and corresponding descriptions are as follows:

$\mathrm{N}$-no appreciable attack: surface may be discolored or etched, but no evidence of pitting or exfoliation;

P-pitting: discrete pits, sometimes with a tendency for undermining and slight lifting of metal at the pit edges;

EA: (superficial) tiny blisters, thin slivers, flakes or powder, with only slight separation of metal;

EB: (moderate) notable layering and penetration into the metal;

EC: (severe) penetration to a considerable depth into the metal;

ED: (very severe) similar to EC except for much greater penetration and loss of metal.

\section{Results and Discussion}

3.1. Determination of Solution Temperature. Differential scanning calorimetry curve (DSC curve) is a technique of measurement for the energy changes between the sample and the reference material with variation of temperature and time. The curve is based on the endothermic and exothermic phenomena accompanied by the physical and chemical changes occurring in the heating process. At the programcontrolled temperature, the function relationship of heat flow rate variation with temperatures was measured, which is commonly used to quantitatively measure melting point and hot melt. From Figure 1, we could find that the solution temperature is $523^{\circ} \mathrm{C}$.

3.2. Effect of Rolling Reduction on Properties of Alloy. To study the deformation ratio on the properties of alloy performance, different reduction ratios were conducted, and both hardness testing and microstructure observation were carried out. As shown in Table 4, after cold rolling, the hardness of alloy increased apparently, especially to initial status.

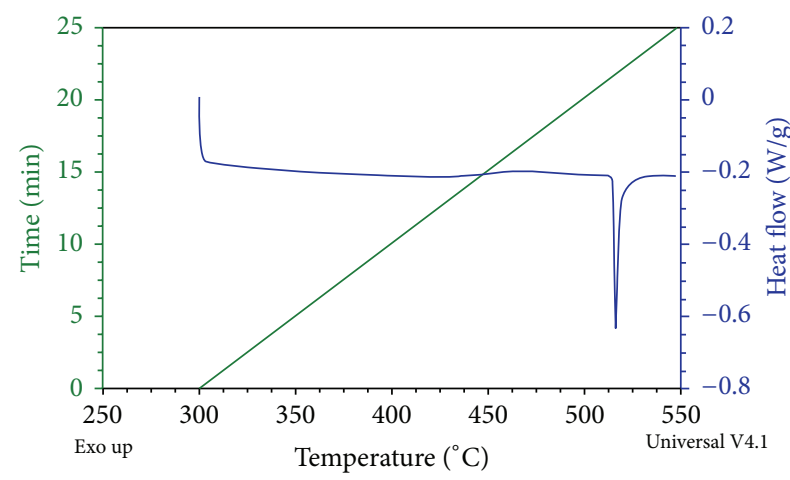

Figure 1: DSC curve of $\mathrm{Al}-4.1 \% \mathrm{Cu}-1.4 \% \mathrm{Mg}$.

As shown in Figure 2, microstructure contrast of alloy with different reduction ratios shows that, with the increase of the deformation rate, the grain sizes become smaller, and their distribution is also more uniform.

3.3. Peak Aging. Mechanical properties after peak aging test at $180^{\circ} \mathrm{C}, 190^{\circ} \mathrm{C}$, and $200^{\circ} \mathrm{C}$ for $2 \mathrm{~h}, 6 \mathrm{~h}$, and $12 \mathrm{~h}$ are shown in Table 5. Variations of properties appear at three different aging temperatures. Mechanical properties of alloy aged at $190^{\circ} \mathrm{C}$ are better than $180^{\circ} \mathrm{C}$ and $200^{\circ} \mathrm{C}$. Therefore, peak aging temperature of alloy is settled as $190^{\circ} \mathrm{C}$.

Mechanical properties of alloy with different aging times at $190^{\circ} \mathrm{C}$ are shown in Table 6 . The tensile strength and yield strength fluctuate with the rise of peak aging time and arrive at peak value after aging for $12 \mathrm{~h}$, and there was not much variation in elongation. As discussed above, the optimum peak aging parameters are settled as $190^{\circ} \mathrm{C}$ for $12 \mathrm{~h}$.

Microstructure of alloy after peak aging was observed, as shown in Figure 3. Initial coarse grains in the alloy are gradually refined and arrive at finest after aging for $12 \mathrm{~h}$. As the aging time increased after peak aging time, the grain sizes grow further, and the grains become coarse again, which also explains why the alloy reached the highest hardness value at the peak aging time of $12 \mathrm{~h}$.

Aging hardening characteristics appear in $\mathrm{Al}-\mathrm{Cu}-\mathrm{Mg}$ aluminum alloy: with the extension of the increase in the aging temperature and aging time, the strength of the alloy increased gradually and declined after the peak aging. Aging intensity variation is caused by the following factors: (1) solid solution strengthening; (2) substrate's recovery and recrystallization; and (3) new phase precipitation [10]. The first 


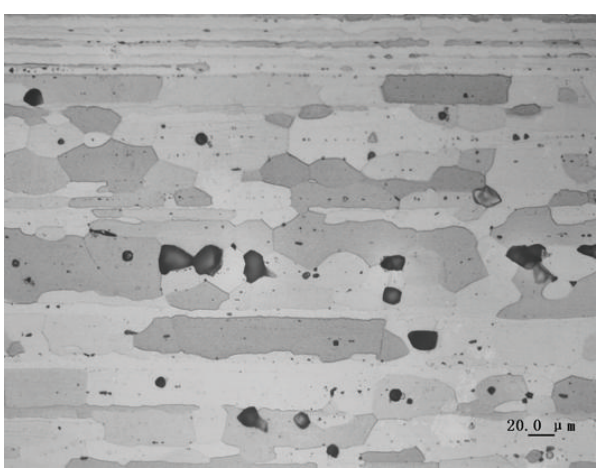

(a)

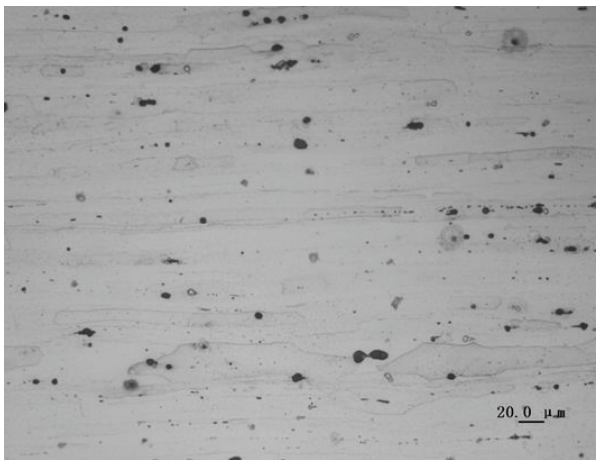

(c)

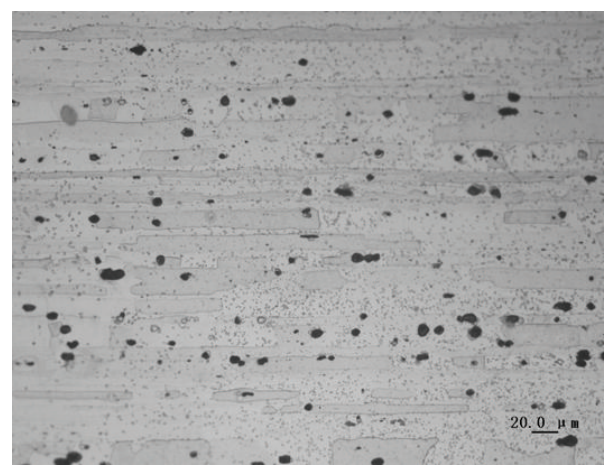

(b)

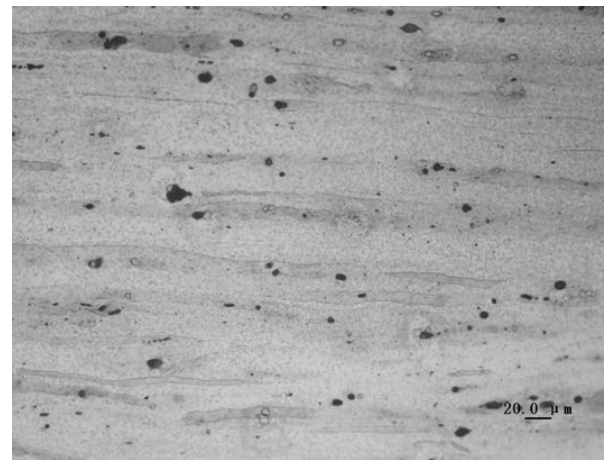

(d)

Figure 2: Comparison of microstructure of alloys after different deformation ratios: (a) without deformation, (b) 30\%, (c) 50\%, and (d) $70 \%$.

TABLE 4: Hardness of alloy before and after different deformation ratios.

\begin{tabular}{lccccc}
\hline Treatment & Initial status & After homogenization & 30\% cold-rolling & 50\% cold-rolling & $70 \%$ cold-rolling \\
\hline Hardness (HV) & 90.1 & 98.6 & 103.8 & 108.2 & 111.7 \\
\hline
\end{tabular}

two factors could make strength decrease with the increasing aging time, while the third factor makes the strength increase, but the strength will fall when the coherent relationship of precipitation phase and the parent phase is destroyed, and the precipitated phase becomes coarse [11]. In the preaging, dispersion precipitates of phase strengthening overweigh softening caused by the other two factors, and therefore the strength is rising and arriving at the peak value. In the later aging, the hardening caused by the precipitation phase is less than the softening caused by the other two factors, therefore, leading to a decreased strength. Some literature also points out that the transition phase $S$ phase $\left(\mathrm{Al}_{2} \mathrm{CuMg}\right)$ is the main aging precipitation strengthening phase of $\mathrm{Al}-\mathrm{Cu}-\mathrm{Mg}$ alloy [12-14]. The strength variation of the alloy during aging is mainly caused by the interaction between the $S$ phase and matrix dislocations [4].

3.4. Stage Aging Test Results. Stage aged aluminum alloy performance test results with four influencing factors are shown in Table 7. The maximum tensile strength is $483.6 \mathrm{MPa}$, while the minimum is $325.1 \mathrm{MPa}$, and the gap between them is 158.5 MPa, which signifies that the effect of different influencing factors on tensile strength is apparent. The yield strength and elongation also show such apparent influence. Different influencing factors have some effects on both hardness and conductivity. For conductivity, the maximum conductivity is $43.8 \%$ IACS, and the minimum is $39.4 \%$ IACS with a difference of $4.4 \%$ IACS.

In this paper we use the consolidated balance multi-index method and range analysis of each indicator in turn and then find a more satisfactory level combination. The effect of first stage aging temperature on mechanical properties is significant. There is some variation in tensile strength and yield strength, but elongation at $105^{\circ} \mathrm{C}$ and $135^{\circ} \mathrm{C}$ is relatively higher, for hardness and conductivity; properties at $135^{\circ} \mathrm{C}$ are better than those at $105^{\circ} \mathrm{C}$. In summary, the optimum first stage aging temperature is $135^{\circ} \mathrm{C}$. Six h or $8 \mathrm{~h}$ is more appropriate for first stage aging time to ensure better mechanical properties. Through range analysis, secondary aging temperature is extremely significant to mechanical properties among four influencing factors. Indicating that in the stabilization stage, the aging temperature is essential to mechanical properties. At $180^{\circ} \mathrm{C}$, strength, elongation, and hardness could be guaranteed, while at $190^{\circ} \mathrm{C}$ the alloy shows a better conductivity. Therefore, $185^{\circ} \mathrm{C}$ is chosen as optimum second stage aging temperature. The alloy achieves optimum 
TABLE 5: Mechanical properties of alloy at different peak aging temperatures.

\begin{tabular}{lccc}
\hline Aging temperature/time & Tensile strength/MPa & Yield strength/MPa & Elongation/\% \\
\hline $180^{\circ} \mathrm{C} / 2 \mathrm{~h}$ & 422.6 & 383.6 & 5.2 \\
$180^{\circ} \mathrm{C} / 6 \mathrm{~h}$ & 428.4 & 387.5 & 5.1 \\
$180^{\circ} \mathrm{C} / 12 \mathrm{~h}$ & 444.1 & 400.4 & 5.0 \\
$190^{\circ} \mathrm{C} / 2 \mathrm{~h}$ & 435.0 & 389.9 & 6.9 \\
$190^{\circ} \mathrm{C} / 6 \mathrm{~h}$ & 426.8 & 373.0 & 5.9 \\
$190^{\circ} \mathrm{C} / 12 \mathrm{~h}$ & 490.4 & 444.8 & 6.0 \\
$200^{\circ} \mathrm{C} / 2 \mathrm{~h}$ & 430.9 & 379.4 & 5.3 \\
$200^{\circ} \mathrm{C} / 6 \mathrm{~h}$ & 442.1 & 382.7 & 5.1 \\
$200^{\circ} \mathrm{C} / 12 \mathrm{~h}$ & 465.8 & 398.7 & 5.7 \\
\hline
\end{tabular}

TABLE 6: Mechanical properties of alloy aged at $190^{\circ} \mathrm{C}$ for different aging times.

\begin{tabular}{|c|c|c|c|c|c|}
\hline Peak aging time/h & Tensile strength/MPa & Yield strength/MPa & Elongation/\% & Hardness/HV & Conductivity/\%IACS \\
\hline 0 & 433.2 & 382.7 & 5.1 & 129.7 & 28.4 \\
\hline 2 & 435.0 & 389.9 & 6.9 & 140.4 & 38.9 \\
\hline 4 & 457.8 & 387.7 & 8.2 & 141.0 & 39.6 \\
\hline 6 & 426.8 & 373.0 & 5.9 & 137.4 & 41.5 \\
\hline 8 & 393.8 & 319.6 & 5.1 & 155.2 & 43.2 \\
\hline 12 & 490.4 & 444.8 & 5.9 & 147.5 & 42.5 \\
\hline 16 & 436.4 & 398.0 & 5.8 & 149.7 & 41.6 \\
\hline 20 & 401.4 & 355.9 & 4.7 & 146.3 & 41.4 \\
\hline 24 & 443.8 & 405.7 & 6.1 & 160.0 & 41.2 \\
\hline
\end{tabular}

TABLE 7: Results of stage aging orthogonal tests.

\begin{tabular}{|c|c|c|c|c|c|c|c|c|c|}
\hline No. & $\mathrm{A}$ & $\mathrm{B}$ & $\mathrm{C}$ & $\mathrm{D}$ & Tensile strength/MPa & Yield strength/MPa & Elongation/\% & Hardness/HV & Conductivity/\%IACS \\
\hline 1 & 1 & 1 & 1 & 1 & 462.8 & 399.0 & 11.4 & 149.7 & 39.4 \\
\hline 2 & 1 & 2 & 2 & 2 & 438.6 & 385.3 & 6.1 & 146.2 & 40.7 \\
\hline 3 & 1 & 3 & 3 & 3 & 398.0 & 350.1 & 7.0 & 132.0 & 41.7 \\
\hline 4 & 1 & 4 & 4 & 4 & 329.3 & 289.9 & 26.4 & 104.9 & 43.8 \\
\hline 5 & 2 & 1 & 2 & 3 & 429.2 & 380.1 & 9.8 & 141.1 & 40.9 \\
\hline 6 & 2 & 2 & 1 & 4 & 450.2 & 393.9 & 11.4 & 152.7 & 39.7 \\
\hline 7 & 2 & 3 & 4 & 1 & 356.3 & 320.4 & 6.9 & 120.7 & 42.6 \\
\hline 8 & 2 & 4 & 3 & 2 & 383.9 & 329.8 & 6.8 & 128.7 & 42.0 \\
\hline 9 & 3 & 1 & 3 & 4 & 389.6 & 349.7 & 3.2 & 126.6 & 42.2 \\
\hline 10 & 3 & 2 & 4 & 3 & 364.0 & 330.2 & 7.9 & 116.3 & 43.0 \\
\hline 11 & 3 & 3 & 1 & 2 & 466.3 & 370.0 & 9.8 & 142.2 & 40.9 \\
\hline 12 & 3 & 4 & 2 & 1 & 430.3 & 381.9 & 13.2 & 140.1 & 41.5 \\
\hline 13 & 4 & 1 & 4 & 2 & 325.1 & 280.0 & 19.7 & 107.4 & 43.6 \\
\hline 14 & 4 & 2 & 3 & 1 & 402.9 & 380.1 & 14.4 & 134.3 & 41.5 \\
\hline 15 & 4 & 3 & 2 & 4 & 397.2 & 344.6 & 6.7 & 141.7 & 40.7 \\
\hline 16 & 4 & 4 & 1 & 3 & 483.6 & 434.8 & 9.7 & 150.7 & 40.0 \\
\hline
\end{tabular}

mechanical properties for second stage aging time of $14 \mathrm{~h}$ or $18 \mathrm{~h}$, so $14 \mathrm{~h}$ is chosen for second stage aging time. Overall, optimum stage aging process is $135^{\circ} \mathrm{C} / 7 \mathrm{~h}+185^{\circ} \mathrm{C} / 14 \mathrm{~h}$.

Through verification by experiment, after stage aging $135^{\circ} \mathrm{C} / 7 \mathrm{~h}+185^{\circ} \mathrm{C} / 14 \mathrm{~h}$, the alloy's mechanical properties are as follows: tensile strength $520.7 \mathrm{MPa}$, yield strength 429.6 MPa, elongation $12.5 \%$, the hardness $151.8 \mathrm{HV}$, and conductivity $41.8 \%$ IACS. The test results show that the orthogonal design is reasonable and appropriate.
3.5. RRA Treatment. While the second stage aging temperature is selected at $240^{\circ} \mathrm{C}$, tensile strength and yield strength achieved the maximum value. Elongation reaches a good level after aging for $40 \mathrm{~min}$. As shown in Table 8, a combination of comprehensive properties that could be achieved after the second stage of RRA is $240^{\circ} \mathrm{C} / 40 \mathrm{~min}$ is as follows: tensile strength 501.6 MPa, yield strength $453.7 \mathrm{MPa}$, elongation 13.1\%, hardness $152.3 \mathrm{HV}$, and conductivity $44.7 \%$ IACS. 


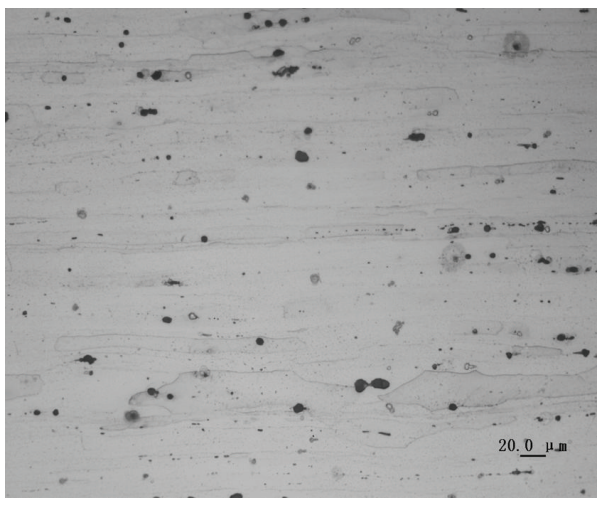

(a)

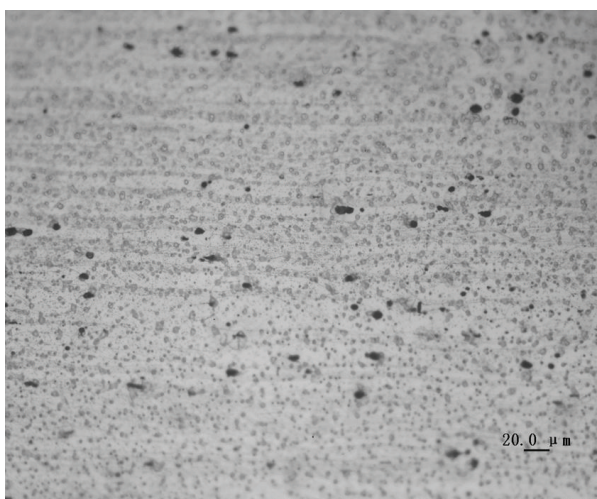

(c)

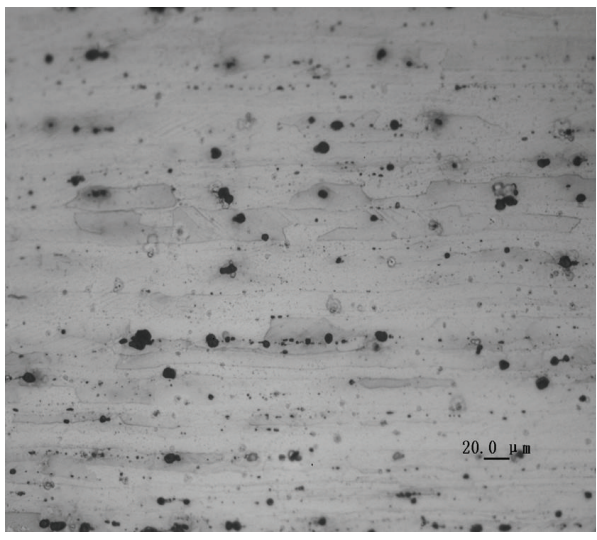

(e)

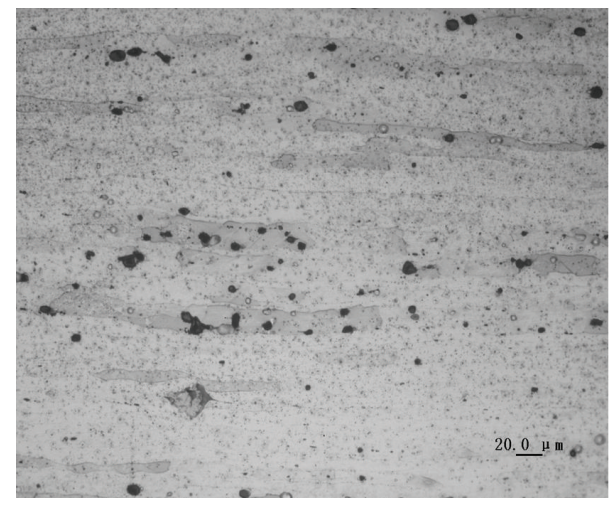

(b)

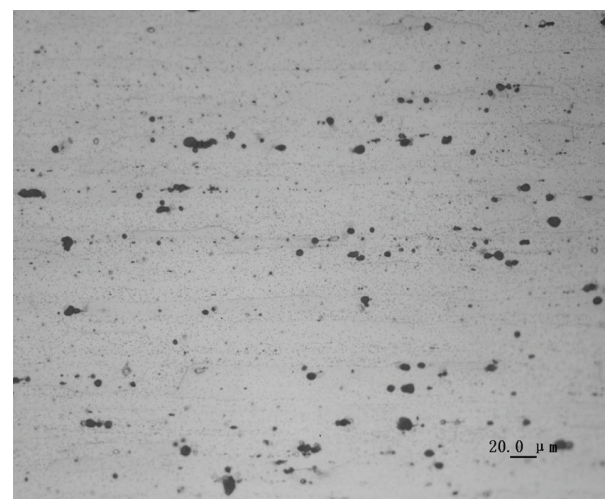

(d)

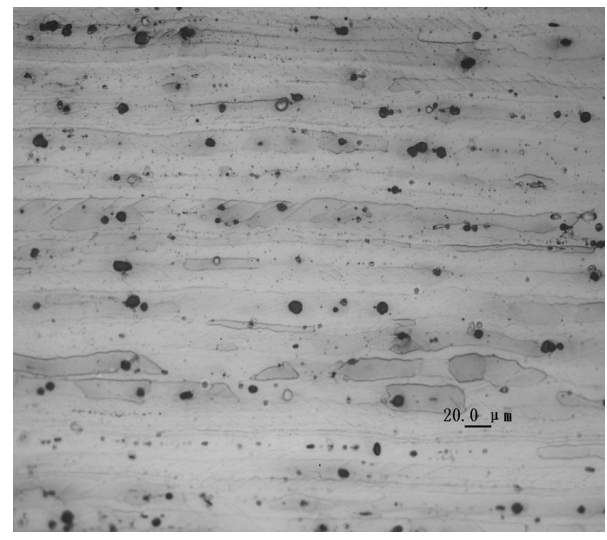

(f)

Figure 3: Effects of different aging times on alloys' microstructure at $190^{\circ} \mathrm{C}$ for (a) $4 \mathrm{~h}$, (b) $8 \mathrm{~h}$, (c) $12 \mathrm{~h}$, (d) $16 \mathrm{~h}$, (e) $20 \mathrm{~h}$, and (f) $24 \mathrm{~h}$.

3.6. Corrosion Test Results. While the second stage aging temperature is selected at $240^{\circ} \mathrm{C}$, tensile strength and yield strength achieved the maximum value. Elongation reaches a good level after aging for $40 \mathrm{~min}$. A combination of comprehensive properties that could be achieved after the second stage of RRA is $240^{\circ} \mathrm{C} / 40 \mathrm{~min}$ is as follows: tensile strength $501.6 \mathrm{MPa}$, yield strength $453.7 \mathrm{MPa}$, elongation $13.1 \%$, hardness $152.3 \mathrm{HV}$, and conductivity $44.7 \%$ IACS.

The sample soaking time is $96 \mathrm{~h}$. Figure 4 shows corrosion morphology after surface cleaning under different aging conditions. As can be seen from Figure 4, different aging schemes affect alloy's corrosion seriously. As immersion time in the EXCO solution increases, exfoliation corrosion becomes more severe. There are varying degrees of exfoliation corrosion at $180^{\circ} \mathrm{C}, 190^{\circ} \mathrm{C}$, and $200^{\circ} \mathrm{C}$ peak aging temperatures, with obvious characteristics of exfoliation corrosion. We selected three two-step aged samples and six regression reaged samples for comparison. Six regression reaged samples in the corrosion test do not show obvious corrosion tendency, but only slight pitting. The cleaned samples were assessed in accordance with ASTM G34-01, and the corrosion level assessment results are shown in Table 9. As can be seen from Table 9, aging scheme of Al-4.1\%Cu-1.4\% Mg aluminum alloy relates closely to. After peak aging treatment, the alloy's corrosion resistance was enhanced, which is still at a low level. Two-step aging improved corrosion resistance at a higher 
TABLE 8: Results of RRA tests.

\begin{tabular}{lccccc}
\hline No. & Tensile strength/MPa & Yield strength/MPa & Elongation/\% & Hardness/HV & Conductivity/\%IACS \\
\hline 1 & 515.1 & 472.3 & 12.1 & 155.9 & 42.8 \\
2 & 506.7 & 474.6 & 13.1 & 152.3 & 44.7 \\
3 & 497.7 & 451.8 & 13.3 & 148.2 & 44.1 \\
4 & 483.6 & 445.0 & 14.2 & 139.6 & 44.5 \\
5 & 463.5 & 421.4 & 15.5 & 134.0 & 45.6 \\
6 & 462.2 & 418.9 & 14.1 & 136.4 & 45.9 \\
\hline
\end{tabular}

TABLE 9: Evaluation of exfoliation corrosion results.

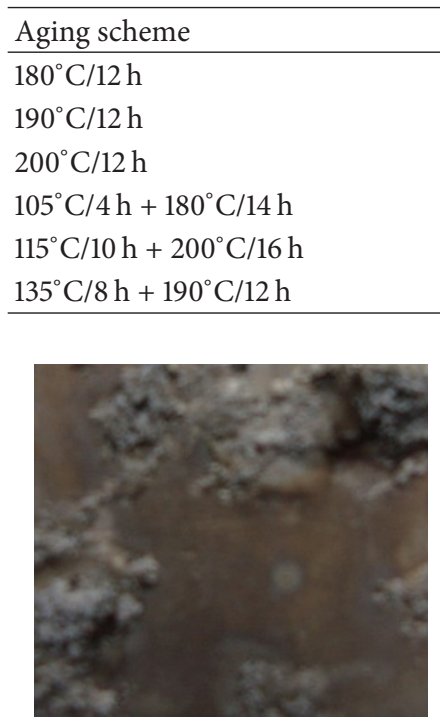

(a)

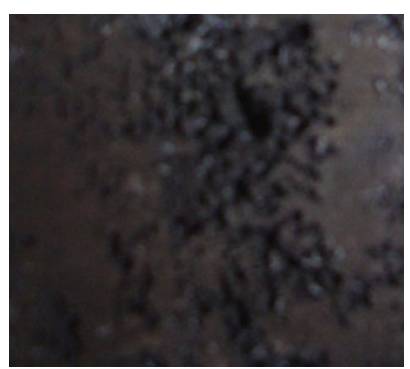

(b)

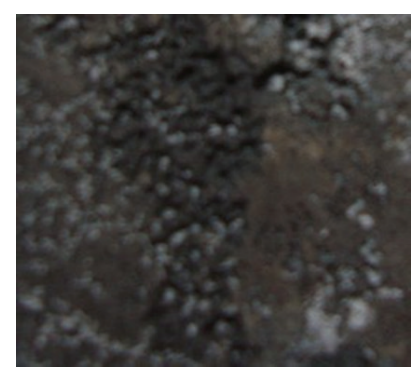

(c)

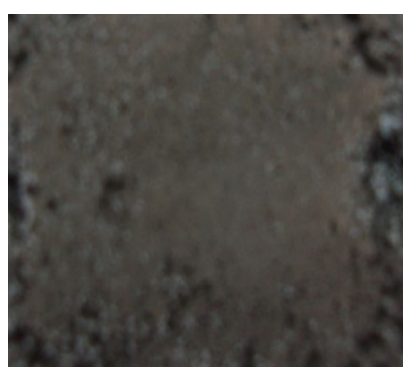

(d)

FIGURE 4: Macrophotograph of exfoliation corrosion: (a) without aging, (b) peak aging, (c) two-step aging, and (d) RRA aging.

level, and RRA significantly improves the alloy's corrosion resistance.

\section{Conclusions}

In this paper, rolling processing and aging heat treatment of $\mathrm{Al}-4.1 \% \mathrm{Cu}-1.4 \% \mathrm{Mg}$ aluminum alloy were carried out. Through comparison of microstructures and mechanical properties, effect of rolling reduction ratios and aging process on alloys was analyzed. Orthogonal experiment was applied in analyzing mechanical and electrical properties, and aging process at certain deformation treatment of alloy was settled, which provides reference for various applications of alloy for future industry. The conclusions are as follows.

(1) Deformation scheme and preheat treatment of Al$4.1 \% \mathrm{Cu}-1.4 \% \mathrm{Mg}$ aluminum alloy are chosen, homogenizing annealing at $430^{\circ} \mathrm{C}$ for $1.5 \mathrm{~h}$, cooling to $250^{\circ} \mathrm{C}$ in furnace at a cooling rate of less than $30^{\circ} \mathrm{C} / \mathrm{h}$ and then cooling to room temperature to make alloy fully annealed. Solid solution temperature of $\mathrm{Al}-4.1 \% \mathrm{Cu}-1.4 \% \mathrm{Mg}$ aluminum alloy is $495^{\circ} \mathrm{C}$. Feasible rolling process is that the alloy is hot-rolled at $470^{\circ} \mathrm{C}$ from $30 \mathrm{~mm}$ to $6.2 \mathrm{~mm}$, and then immediately solid solution at $495^{\circ} \mathrm{C}$ for $1 \mathrm{~h}$, then cold-rolled to $1.4 \mathrm{~mm}$ sheet at room temperature.
(2) After tested deformation, the optimum peak aging process of $\mathrm{Al}-4.1 \% \mathrm{Cu}-1.4 \% \mathrm{Mg}$ aluminum alloy is determined: $190^{\circ} \mathrm{C} / 12 \mathrm{~h}$. Properties after the above peak aging process are as follows: tensile strength $490.4 \mathrm{MPa}$, yield strength $444.8 \mathrm{MPa}$, elongation $5.95 \%$, hardness $147.5 \mathrm{HV}$, and conductivity $42.5 \%$ IACS. Optimum strength with low elongation was obtained after peak aging treatment.

(3) After tested deformation, the optimum stage aging process of $\mathrm{Al}-4.1 \% \mathrm{Cu}-1.4 \% \mathrm{Mg}$ aluminum alloy is determined: $135^{\circ} \mathrm{C} / 7 \mathrm{~h}+185^{\circ} \mathrm{C} / 14 \mathrm{~h}$. Properties after the above stage aging process are as follows: tensile strength $520.7 \mathrm{MPa}$, yield strength $429.6 \mathrm{MPa}$, elongation $12.5 \%$, hardness $151.8 \mathrm{HV}$, and conductivity $41.8 \%$ IACS. Both strength and elongation are improved after stage aging.

(4) After tested deformation, the optimum RRA process of $\mathrm{Al}-4.1 \% \mathrm{Cu}-1.4 \% \mathrm{Mg}$ aluminum alloy is determined: $190^{\circ} \mathrm{C} / 12 \mathrm{~h}+240^{\circ} \mathrm{C} / 40 \mathrm{~min}+190^{\circ} \mathrm{C} / 12 \mathrm{~h}$. Properties after the above stage aging process are as follows: tensile strength 501.6 MPa, yield strength 453.7 MPa, elongation 13.1\%, hardness $152.3 \mathrm{HV}$, and conductivity 44.7\% IACS. Both mechanical properties and conductivity were enhanced after RRA treatment.

(5) Aging scheme is closely related to corrosion resistance of $\mathrm{Al}-4.1 \% \mathrm{Cu}-1.4 \% \mathrm{Mg}$ aluminum alloy, and three different 
aging schemes can improve the corrosion resistance. The exfoliation corrosion evaluation results show that the aging effect on exfoliation corrosion ability order is RRA > two-step aging $>$ peak aging.

\section{Acknowledgments}

The financial support of the National Natural Science Foundation of China (51174057, 51274062) and the National High Technology Research and Development Program (2012AA03A503) is greatly acknowledged.

\section{References}

[1] Z. Huda and P. Edi, "Materials selection in design of structures and engines of supersonic aircrafts: a review," Materials and Design, vol. 46, no. 4, pp. 552-560, 2013.

[2] N. Gao, M. J. Starink, N. Kamp, and I. Sinclair, "Application of uniform design in optimisation of three stage ageing of Al-CuMg alloys," Journal of Materials Science, vol. 42, no. 12, pp. 43984405, 2007.

[3] R. Gu and A. H. W. Ngan, "Size effect on the deformation behavior of duralumin micropillars," Scripta Materalia, vol. 68, no. 11, pp. 861-864, 2013.

[4] K. D. Ralston, N. Birbilis, M. Weyland, and C. R. Hutchinson, "The effect of precipitate size on the yield strength-pitting corrosion correlation in Al-Cu-Mg alloys," Acta Materialia, vol. 58, no. 18, pp. 5941-5948, 2010.

[5] R. Ferragut, A. Dupasquier, C. E. Macchi, A. Somoza, R. N. Lumley, and I. J. Polmear, "Vacancy-solute interactions during multiple-step ageing of an Al-Cu-Mg-Ag alloy," Scripta Materialia, vol. 60, no. 3, pp. 137-140, 2009.

[6] F. Bardi, M. Cabibbo, and S. Spigarelli, "An analysis of thermomechanical treatments of a 2618 aluminium alloy: study of optimum conditions for warm forging," Materials Science and Engineering A, vol. 334, no. 1-2, pp. 87-95, 2002.

[7] Y. J. Huang, Z. G. Chen, and Z. Q. Zheng, "A conventional thermo-mechanical process of $\mathrm{Al}-\mathrm{Cu}-\mathrm{Mg}$ alloy for increasing ductility while maintaining high strength," Scripta Materialia, vol. 64, no. 5, pp. 382-385, 2011.

[8] F. Tariq, N. Naz, R. A. Baloch, and F. Faisal, "Characterization of material properties of $2 \mathrm{xxx}$ series al-alloys by non destructive testing techniques," Journal of Nondestructive Evaluation, vol. 31, no. 1, pp. 17-33, 2012.

[9] B. M. Cina, "Reducing the susceptibility of alloys, particularly aluminium alloys, to stresss corrosion cracking[P]," 1974-12-24 US Patent No. 3, 856, 584.

[10] K. M. Knowles and W. M. Stobbs, "the structure of 111 age hardening precipitates in Al-Cu-Mg-Ag alloy," Acta Crystallographica Section B, vol. 44, no. 3, pp. 207-227, 1988.

[11] Y. Nagai, M. Murayama, Z. Tang, T. Nonaka, K. Hono, and M. Hasegawa, "Role of vacancy-solute complex in the initial rapid age hardening in an Al-Cu-Mg alloy," Acta Materialia, vol. 49, no. 5, pp. 913-920, 2001.

[12] T. S. Parel, S. C. Wang, and M. J. Starink, "Hardening of an Al$\mathrm{Cu}-\mathrm{Mg}$ alloy containing Types I and II S phase precipitates," Materials and Design, vol. 31, no. 1, pp. S2-S5, 2010.

[13] A. K. Shukla and W. A. Baeslack III, "Orientation relationships and morphology of S phase in friction stir welded $\mathrm{Al}-\mathrm{Cu}-\mathrm{Mg}$ alloy," Journal of Materials Science, vol. 44, no. 2, pp. 676-679, 2009.
[14] S. C. Wang and M. J. Starink, "Two types of S phase precipitates in Al-Cu-Mg alloys," Acta Materialia, vol. 55, no. 3, pp. 933-941, 2007.

[15] K. D. Ralston, N. Birbilis, M. Weyland, and C. R. Hutchinson, "The effect of precipitate size on the yield strength-pitting corrosion correlation in Al-Cu-Mgalloys," Acta Materialia, vol. 58, no. 18, pp. 5941-5948, 2010. 

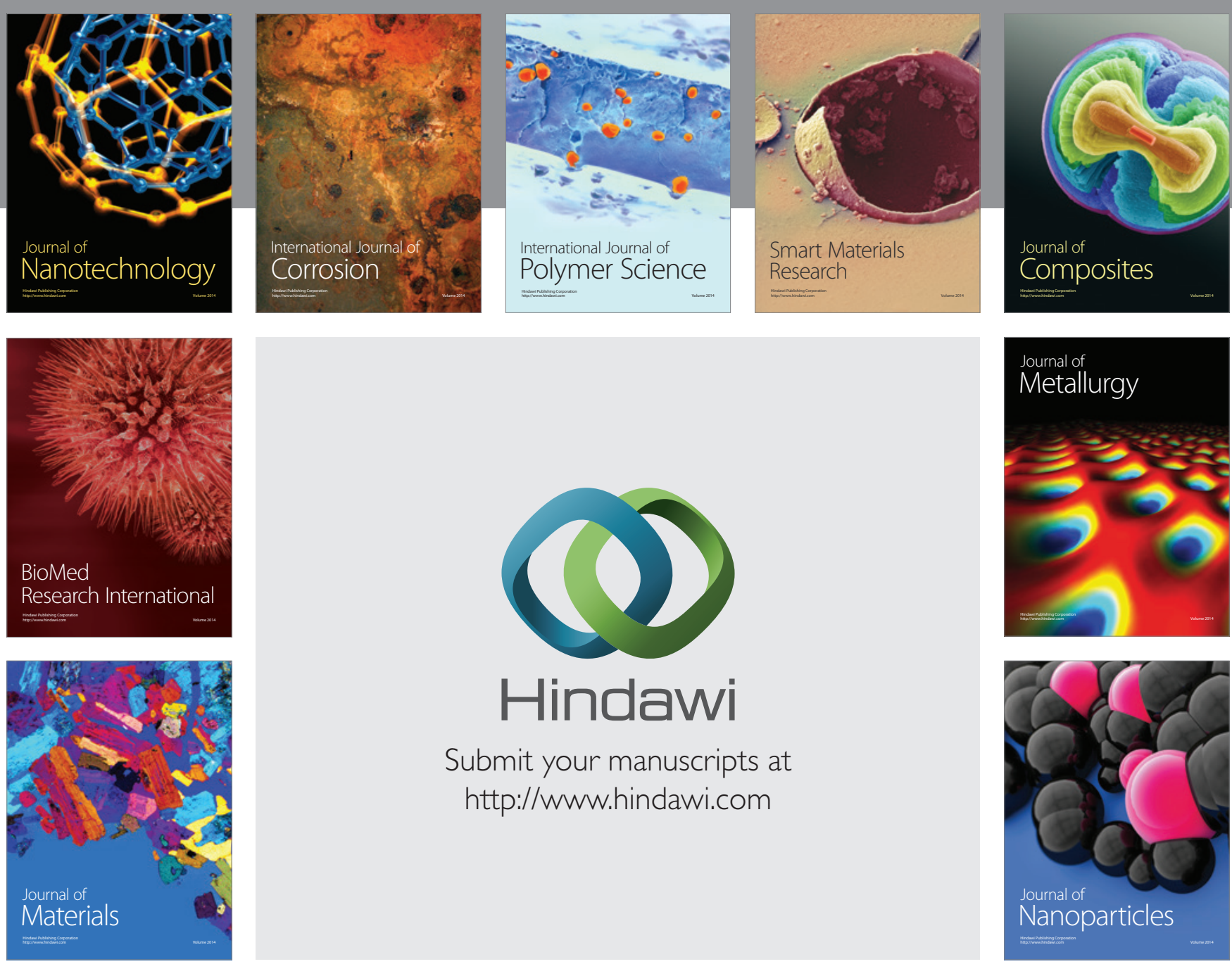

Submit your manuscripts at http://www.hindawi.com
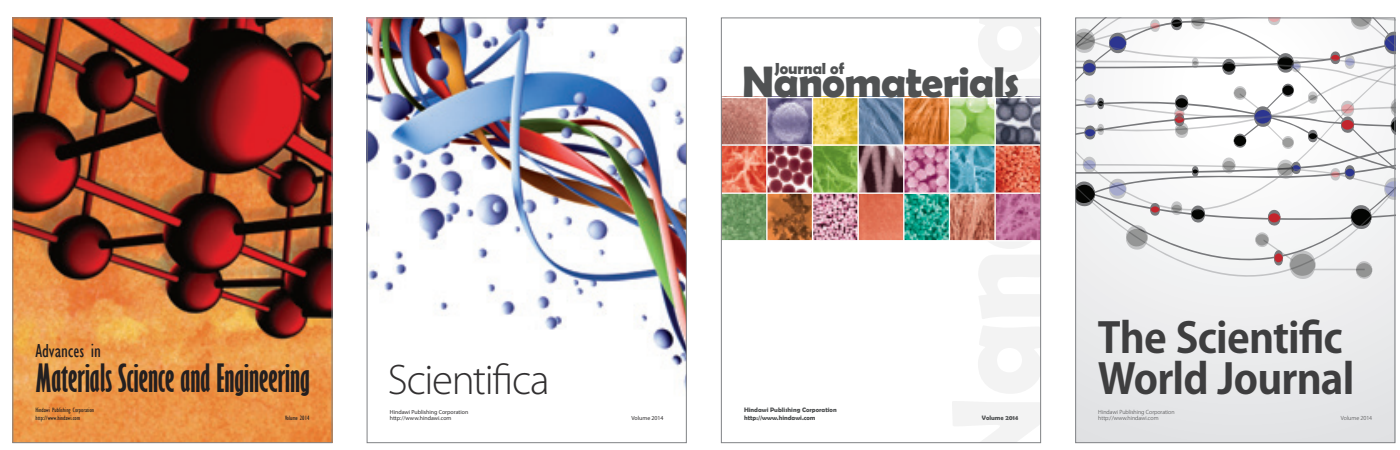

\section{The Scientific World Journal}
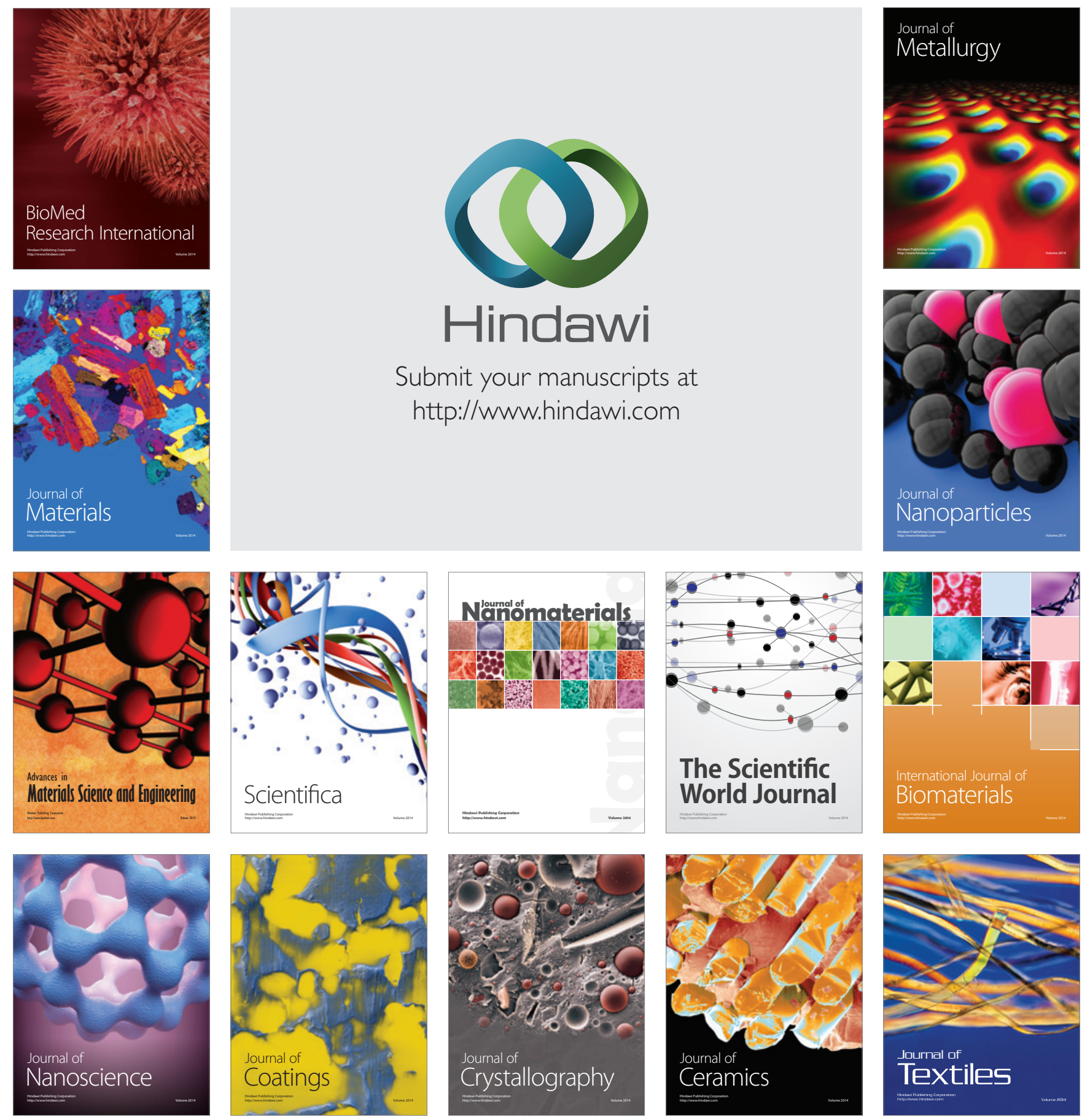